\title{
Evaluating the Design and Repeatability of a Novel Device to Measure Friction of Mechanical Surrogate Skins in Contact with Cotton Textiles
}

\author{
Mevra Temel $^{1,2}$ (D) Alex B. Lloyd ${ }^{1,2}$ (D) Andrew A. Johnson ${ }^{1}$ (D
}

Received: 28 May 2021 / Accepted: 14 August 2021 / Published online: 23 August 2021

(c) The Author(s) 2021

\begin{abstract}
The ability to measure the level of friction between the human skin and a given textile is critical across fashion and textiles sectors, not least for the development of sporting and protective clothing. A portable custom-made device capable of measuring friction during the skin-textile interaction across often difficult or impossible to investigate body regions with objective repeatability has been established. The friction between a pre-shrunk $100 \%$ cotton textile and a quantity of four control surfaces (transparent and patterned polycarbonate plastic, and silicon and lorica surrogate skin) was measured three times per day across five consecutive days. The results clearly demonstrated that the novel friction test device had an excellent repeatability of 0.94 and 0.93 intraclass corelation coefficient for static and dynamic friction coefficient measurement, respectively. The silicon surrogate skin control surface produced the highest friction coefficient, while the pattered polycarbonate plate demonstrated the lowest friction coefficient, suggesting that the physical features of the control surface material influenced the recorded coefficient of friction. It was also revealed that the relationship between the static and dynamic friction coefficient is dependent on the surface material.
\end{abstract}

Keywords Product design $\cdot$ Skin friction $\cdot$ Repeatability $\cdot$ Friction behaviour

\section{Abbreviations \\ COF The coefficient of friction. \\ RPSD Relatively polled standard deviation. \\ ICC Interclass corelation intra-class correlation}

\section{Introduction}

The skin is the largest organ of the human body, substantial elements of which are in regular contact with a range of textiles such as clothing, sheets, or towels, throughout the day. The skin and fabric interaction system provides a thermal and sensorial state of comfort, and maintains the healthy physical state of an individual [1]. Understanding local thermal, mechanical and wetness perception to external stimuli, as well as the level of friction during the skin-textile interaction is essential when investigating the comfort of clothing

Andrew A. Johnson

a.johnson@lboro.ac.uk

1 School of Design and Creative Arts, Loughborough University, Loughborough, UK

2 Environmental Ergonomics Research Centre, Loughborough University, Loughborough, UK
[2-10]. In addition, it is widely known that the occurrence of undesirable levels of skin friction has the potential to generate skin-related health problems such as irritations, abrasions, and blisters [11-14].

Researchers have recently evaluated the skin's response to textiles with regards to protective clothing, sportswear, and healthcare textiles [8, 15-19]. However, published literature relating to the measurement of friction during skintextile interaction is limited. To measure the friction between the skin and other materials, large laboratory set-ups have been used in a small number of studies. An advantage of such traditional tribological equipment is their ability to be used to assess the skin's frictional properties without dedicated test apparatus [20, 21]. However, with the use of such traditional tribological laboratory set-ups, comes the often limited range of body regions able to be measured, typically the distal upper or distal lower limbs [22, 23]. Understanding the regional differences of friction at the skin-textile interaction across various body locations is crucial to mitigating the occurrence and impact of health-related dermatological problems and sensorial discomfort. By determining the regions of the body that may be sensitive to friction and touch sense, scientists, engineers, and designers can be fully informed from the outset of the product development 
process. Some portable devices measuring regional skin friction have previously been proposed [17, 23-25]. While the portability of these devices may facilitate measurements of skin friction at a range of body regions, they have demonstrated to be limited when measuring friction during skin-textile interactions due to a range of factors, including methods and ease of textile attachments as well as the incorporated rotational test method (variable contact velocities) [17, 21, 23-25]. Therefore, a reliable, repeatable, and convenient device, and associated test method, are required for the measurement of skin friction when in contact with a textile across a wide range of body regions.

Therefore the objective of this study was fourfold: (i) to describe the design of a new friction testing device for measuring friction in skin-textile interactions, (ii) to evaluate the repeatability of static and dynamic friction coefficient of four control surfaces in contact with a cotton textiles using the new friction testing device, (iii) to determine whether the friction coefficient is affected by the type of control surfaces i.e. surrogate skins, (iv) to determine whether the relationship between the static and dynamic friction is affected by the type of control surfaces.

\section{Friction Test Apparatus Description}

The novel device, as presented in Fig. 1, is a portable handheld device developed to measure friction between the human skin and selected test materials. The device measures approximately $230 \times 150 \times 90 \mathrm{~mm}(l \times h \times d)$ and weighs approximately $0.5 \mathrm{~kg}$. It enables researchers to gather measurements across various body sites with relative ease when compared to established alternative apparatuses. The device consists of two primary elements - the main body, which includes data acquisition apparatus, and its supplementary analogue and digital converter, as represented in Fig. 1.

The main data acquisition hub includes two housings (a) and two handles on the top (b) and left-hand side (c) of the body. A $35 \mathrm{~mm}$ diameter porcelain ceramic knob (d) is used as a contact probe. Seven coloured LED indicators located on top of the main body of the device indicates:

- A green light (e) where normal forces are achieved (typically $2 \mathrm{~N}$ ).

- Blue lights (f) which indicate that force values are lower than the target force.
Fig. 1 Novel skin friction measurement device schematic

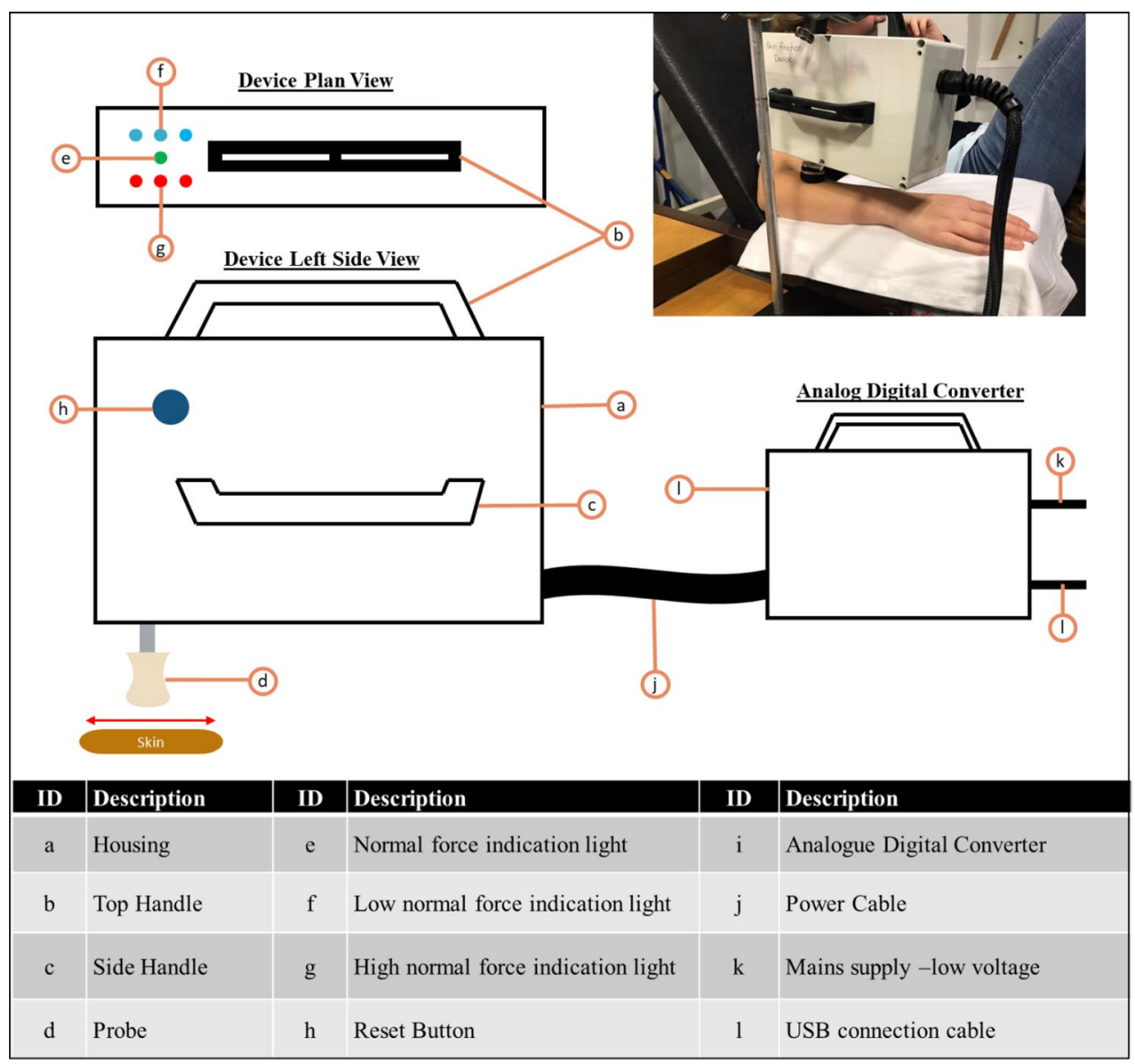


- Red lights (g) which indicate when force values are higher than required.

A pre-programmed target normal force can be set in the software and these LEDs indicate to the user the variance between the actual and the desired applied force. The user can then modulate this applied force approximately accurately and as necessary. A reset button (h) is placed on the left-hand side of the device body and can be used to tare zero the value of normal and friction forces. An analogue-digital converter (l) provides a power supply to the main data acquisition hub via power cable $(\mathrm{k})$, while cable $(\mathrm{j})$ is used to connect the analogue-digital converter to the data acquisition box and a USB (l) cable is used for exporting acquired data from the device.

\subsection{Hardware}

As presented in Fig. 2, the developed skin friction measurement device is equipped with two cantilever $100 \mathrm{~g}$ straight bar mini-load cells (Digi-Key Electronics, UK) which were used to measure both normal (1) and friction forces (2) independently and electronically.

A DC geared motor with a maximum output speed of 140-rpm, 12 V DC supply voltage, and $20 \mathrm{Nm}$ maximum output torque (RS Components Ltd. UK) (3) was used to facilitate horizontal movement. A tacho-generator, essentially a motor used in reverse mode (Portescap DC Motor) with a $5600 \mathrm{rpm}$ output speed, $6 \mathrm{~V}$ DC supply voltage, and an $8.4 \mathrm{Nm}$ maximum output torque (RS Components Ltd. UK), (4) was placed between the crank (5) and motor to control the speed of the mechanism via a PID control loop implemented in software, to prevent spin fluctuations and maintain a steady spin rate. This set-up allowing it to be independent of retarding force as well as facilitating measurements even at low speeds. Also, a potentiometer/linear transducer (6) was used to determine probe horizontal displacement.

The fundamental functionality of the hardware system is described as follows: As the device is pressed on to the test surface (skin), the probe will move vertically towards the underside of the device via linear bearing (8). Once initiated, the spring (7) is stretched, and the load cell (1) measures the normal force as illustrated in Fig. 2 (Panel A). Following and as represented in Fig. 2 (Panel B), a second linear bearing (9) allows the probe to make a reciprocating movement. When the probe and contact surface interact, friction force occurs, at which point the load cell (10) measures this friction force.

\subsection{Software}

The device was programmed using the DASYLab (2016, USA) a graphical programming environment. The graphical user interface was developed to support user operation of the novel friction measurement device. A graphical display was
Fig. 2 The working principle of the normal force system (a) and friction force system (b)

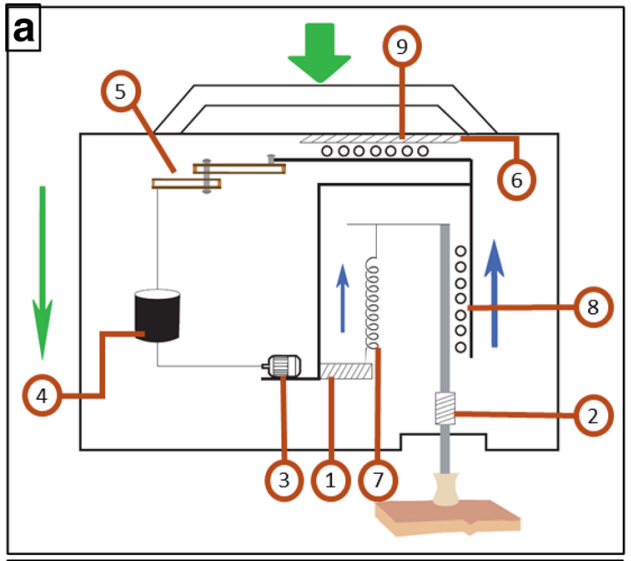

Normal force measurement: Pressing the device on the skin, and probe moves up. Once spring stretches, load cell measures normal force.

\begin{tabular}{|c|l|r|l|l|l|}
\hline ID & Description & ID & Description & ID & Description \\
\hline 1 & Load cell (for normal force) & 4 & Tacho-generator & 7 & Spring \\
\hline 2 & Load cell ( for drag force) & 5 & Crank & 8 & Linear bearing \\
\hline 3 & DC geared motor & 6 & Potentiometer & 9 & Linear bearing \\
\hline
\end{tabular}

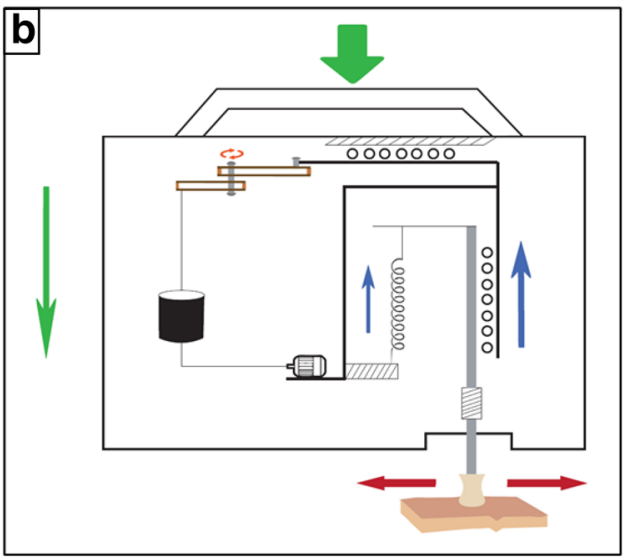

Friction force measurement: Running motor gives horizontal movement to probe. When probe and skin interact, friction force occurs and load cell measures this friction force. 
included to display key measurements including the recorded normal force $(\mathrm{N})$, friction force $(\mathrm{N})$, displacement $(\mathrm{cm})$, and coefficient of friction. The normal load $\left(\mathrm{F}_{\text {normal }}\right)$ and friction force $\left(\mathrm{F}_{\text {friction }}\right)$ are registered in real-time by strain gauge force sensors. The forces measured by the developed software were calibrated using a Class M2 calibration weight set. Data were sampled in the board data acquisition system at a frequency $\left(f_{\text {sample }}\right)$ of $2 \mathrm{kHz}$. Typically measured force signals are shown in Fig. 3.

In Fig. 3 (top), the dashed line indicates the applied normal force; the line represents the measured friction force, and in Fig. 3 (bottom), the line represents the friction coefficient. The device works by reciprocating movement of the probe, and the positive values are the friction coefficient generated when the probe moves towards the indication lights side (forwards) while the negative values are the friction coefficient generated when the probe moves towards the power cable side (backwards). As seen in Fig. 3, 10 cycles
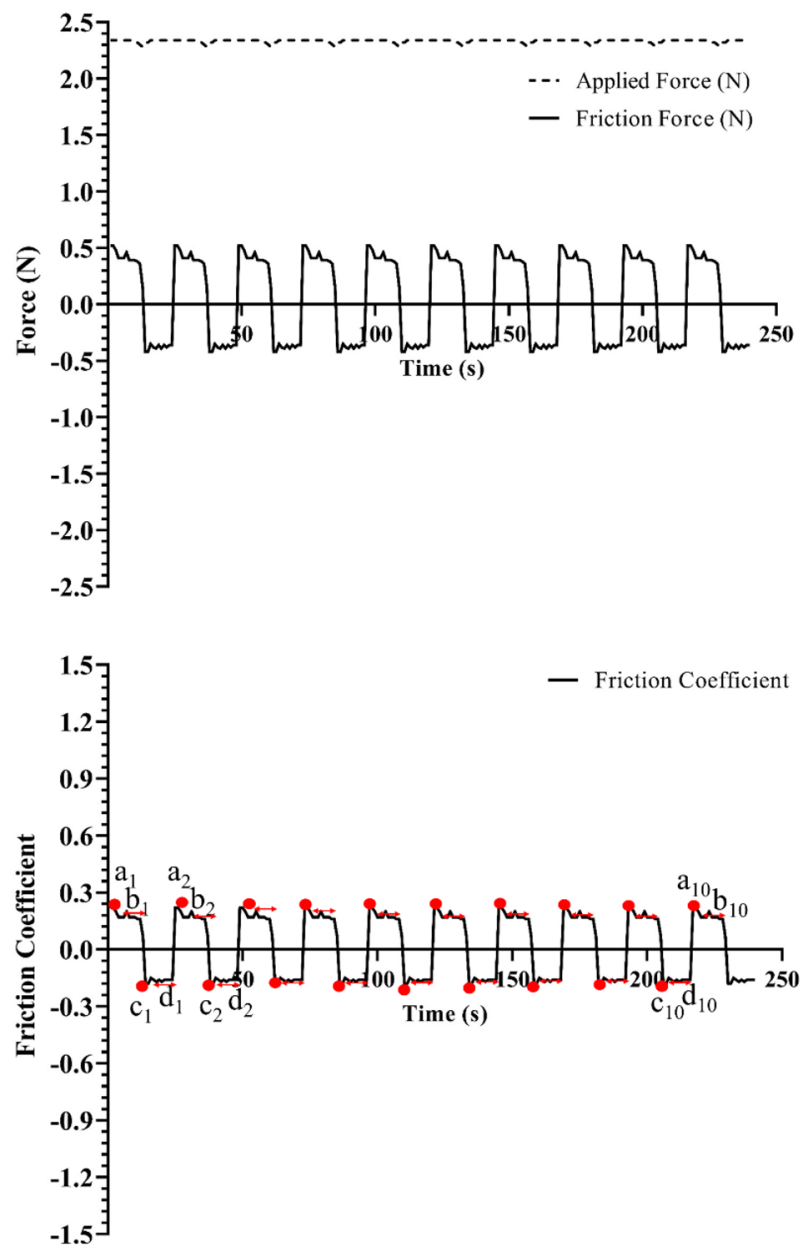

Fig. 3 Typical friction measurement outputs for normal and fiction force (top) and friction coefficient (bottom). The conduct surface was Lorica skin, and $0.04 \mathrm{~m} / \mathrm{s}$ velocity $(v)$ was used over a $40 \mathrm{~mm}$ moving surface were produced in each application. The mean of peak points in the recorded COF, as represented by $(\mathrm{a} 1, \mathrm{a} 2, \ldots, \mathrm{a} 10)$ in Fig. 3 (bottom), was measured as the forwards static friction coefficient, while the stable point in the COF line was measured as the forwards dynamic friction coefficient, as represented by (b1, b2, ..., b10) in Fig. 3 (bottom). For backwards measurements, the static friction coefficient was measured via calculating the mean of the peak points, represented by "c1, c2, .., c10" and dynamic friction coefficient was calculated via taking a mean of the stable points, represented by "d1, d2, ..., d10" in Fig. 3 (bottom).

\section{Methods}

\subsection{Textile Samples}

Within this investigation, pre-shrunk $100 \%$ cotton single jersey samples were selected as the contact material, as shown in Fig. 4 (Panel a, b). The thickness and weight of these
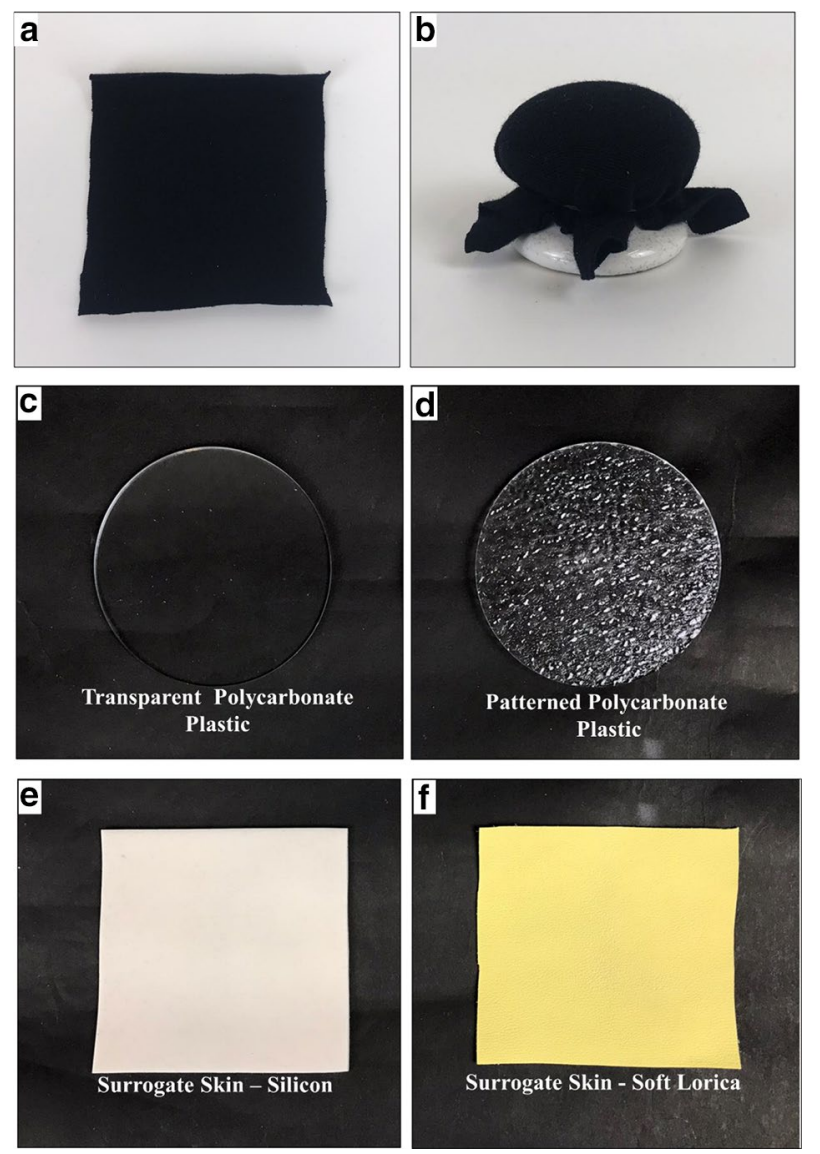

Fig. 4 Textile specimen before attached to the probe (a), attached to the probe (b) and contact surfaces used in the experiment: transparent polycarbonate plastic (c), patterned polycarbonate plastic (d), surrogate skin - silicon (e), surrogate skin - soft lorica (f) 
samples were $0.62 \mathrm{~mm}$ and $140 \mathrm{~g} / \mathrm{m} 2$, respectively. Also, surface roughness was recorded at $3.7 \mu \mathrm{m}$ by Raccuglia et al. [15]. Each textile sample measured $80 \times 80 \mathrm{~mm}$ in length and width with a virgin textile sample used every three applications. The samples were affixed to the probe surface via an adhesive spray and a rubber band. Extensive pilot studies showed that this method of attaching the textile to the probe did not influence static and dynamic skin friction coefficient. Before each measurement, control measurements were taken by measuring the friction coefficient between each textile attached to its respective probe and a control surface to ensure that the textile was appropriately affixed to the test probe.

\subsection{Contact Surfaces}

For the contact control surfaces, both transparent polycarbonate (PALSUNPLUSC-Bay Plastics Ltd, UK) as shown in Fig. 4 (Panel c) and patterned polycarbonate plastic (PALSUNPAG-Bay Plastics Ltd, UK) measuring $100 \mathrm{~mm}$ in diameter (Panel d), silicon surrogate skin measuring $100 \times 100 \mathrm{~mm}$ in length and width (Reelskin, UK) (Panel e), and a soft Lorica artificial leather known for possessing similar skin friction coefficient with human skin (EhrlichLeder, Germany) [7] (Panel f).

To assess the friction device's test-retest reliability, the contact surface was required to have consistent physical features that could potentially influence recorded friction force values.

\subsection{Experiment Set-Up}

The experimental set-up, as displayed in Fig. 5, included the friction device, a custom-made holding frame, contact material (100\% cotton textile) and contact control surfaces (transparent and patterned polycarbonate plastic, silicon and Lorica surrogate skin). The friction device was placed within a custom-made frame to ensure stability of the device while the probe was in contact with the contact surface.

\subsection{Test Protocol}

The experiment was conducted across five consecutive days using a fixed experimental set-up as previously shown in Fig. 5. All measurements were performed at an environmental temperature of $25^{\circ} \mathrm{C}$ and $50 \%$ relative humidity. The first sample was attached to the friction device, and the device placed in the holding frame. The first control contact surface material was affixed to the test platform and placed beneath the probe, and the applied force was adjusted by the developed tracking software. Once the applied force was adjusted to target force, testing was initiated to measure static and dynamic friction coefficient. This process was repeated three

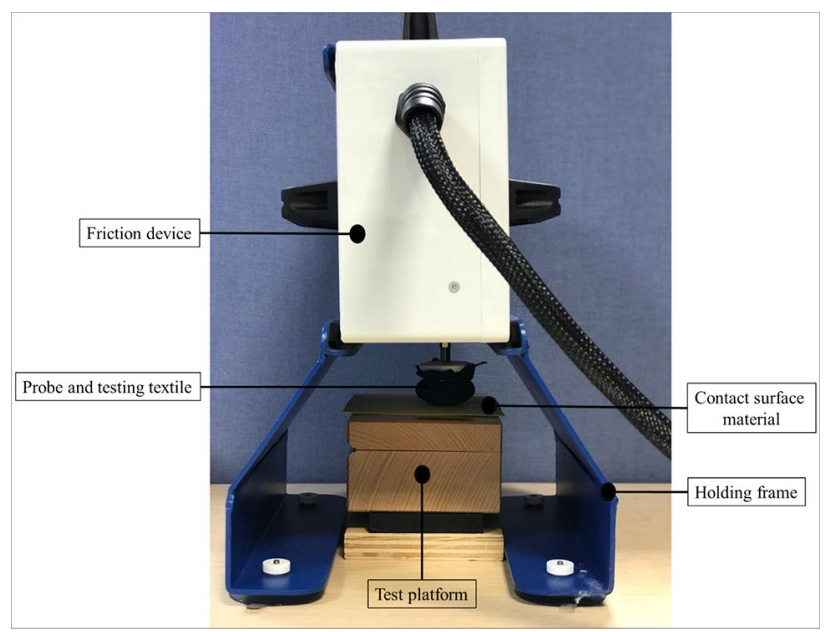

Fig. 5 Experimental set-up for friction measurement in textile-contact surface interaction

times for each contact surface material, and in total 60 tests (600 cycles) were conducted. A normal load of $2.42 \pm 0.05 \mathrm{~N}$ ( $5 \mathrm{kPa})$ was applied to control surfaces $(d=25 \mathrm{~mm})$ with a $0.04 \mathrm{~m} / \mathrm{s}$ velocity $(v)$ over a $40 \mathrm{~mm}$ moving surface. $0.04 \mathrm{~m} / \mathrm{s}$ velocity was used because it is approximately in the middle of pleasantness range [26].

\subsection{Data Analysis}

The friction coefficient $(\mu)$ was calculated from the ratio of the friction force and the normal force: $\mu=F_{\text {friction }} / F_{\text {normal. }}$. For all measurements, the friction coefficient was calculated in time.

The repeatability of the novel friction measurement device was assessed using relative pooled standard deviation (RPSD) and interclass correlation coefficient (ICC). This was based on an absolute agreement, two-way mixed-effects model [27], which describes how strongly units in the same group resemble each other. The pooled standard deviation (RPSD) was used to show the extent of variability concerning the mean of the population during the five days:

The pooled standard deviation (RPSD)

$R P S D=\frac{\sqrt{\left(n_{1}-1\right) s_{1}{ }^{2}+\left(n_{2}-1\right) s_{2}{ }^{2}+\cdots+\left(n_{5}-1\right) n_{5}{ }^{2}}}{n_{1}+n_{2}+\cdots+n_{5}}$

Interclass correlation coefficient (ICC) was used to describe how strongly units in the same group resembled each other. RPSD and ICC estimates were calculated using SPSS statistical package version 24.0 (SPSS Inc, Chicago, IL) based on a mean-rating $(k=3)$, absolute agreement, 2-way mixed-effects model [27]. 


\section{Results}

\subsection{The Friction Coefficient Across Four Control Surfaces}

The static and dynamic friction coefficient between patterned polycarbonate contact surface and the $100 \%$ cotton textile was measured at $0.17 \pm 0.02$ and $0.16 \pm 0.02$, respectively, which were the lowest recorded static and dynamic COF values across all four-contact surface materials as shown in Table 1. Following, the COF of the transparent polycarbonate and lorica leather surrogate skin were $0.18 \pm 0.01$ and $0.25 \pm 0.01$, respectively for static COF and $0.16 \pm 0.02$ and $0.17 \pm 0.01$, respectively for dynamic COF. The highest recorded static and dynamic COF values were recorded when contact was made with the silicon surrogate skin contact material, with $0.91 \pm 0.03$ and $0.81 \pm 0.03$, respectively.

\subsection{The Repeatability of the Novel Friction Device}

The static and dynamic COF between contact surfaces (transparent, polycarbonate, patterned polycarbonate, silicon and Lorica surrogate skin) and contact material (100\% cotton textile) were measured three times each day across five consecutive days - the results of which are outlined in Table 2.

Table 2 demonstrates excellent level repeatability across the four-contact surface static and dynamic friction coefficient. The newly established device demonstrated a high degree of reliability with an RPSD of $2.2 \%$ and ICC of 0.95 when recording static COF, and an RPSD of $4.5 \%$, and ICC of 0.92 for dynamic COF when the cotton test textile was in contact with the transparent polycarbonate.

\subsection{The Relationship Between Static and Dynamic Friction Coefficient}

The attainted static COF values were always greater than that of the dynamic COF for each contact surface material tested within this study. The static and dynamic friction coefficient linearly correlated while the cotton textile was interacting with control contact materials, transparent, patterned polycarbonate, surrogate skin-silicon and Lorica $\left(r^{2}=0.86, r^{2}=0.97, r^{2}=0.93\right.$ and $r^{2}=0.97$, respectively $)$. The relationship between the static and dynamic COF are displayed in Fig. 6.

The average difference between the static and dynamic friction coefficient was $0.032,0.034,0.086$ and 0.1 for transparent, patterned polycarbonate, surrogate skin - silicon and Lorica, respectively.

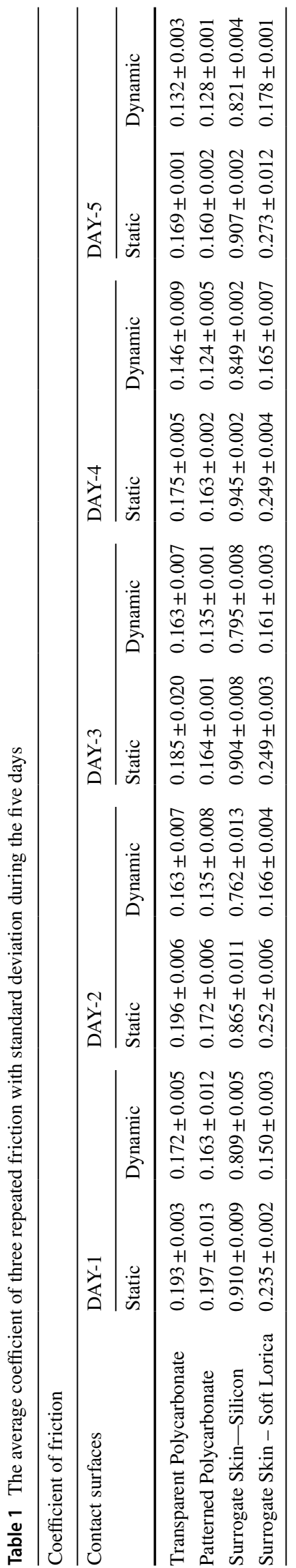


Table 2 The relative pooled standard deviation and interclass correlation coefficient of friction device measurements for the four-contact surface materials

\begin{tabular}{lllllll}
\hline & \multicolumn{2}{l}{ RPSD (\%) } & & \multicolumn{2}{l}{ ICC } \\
\cline { 2 - 3 } \cline { 6 - 7 } Contact surfaces & Static & Dynamic & & Static & Dynamic \\
\hline Transparent polycarbonate & 2.24 & 4.58 & & 0.95 & 0.93 \\
Patterned polycarbonate & 3.62 & 4.86 & & 0.92 & 0.91 \\
Surrogate skin—silicon & 2.12 & 2.18 & & 0.93 & 0.90 \\
Surrogate skin—soft lorica & 0.88 & 0.97 & & 0.97 & 0.97 \\
\hline
\end{tabular}

\section{Discussion}

This study sought to examine the validity and repeatability of static and dynamic friction coefficient between a cotton textile and four control surfaces materials included transparent and patterned polycarbonate plastic, silicon and lorica surrogate skin using a novel friction testing device. Repeatability evaluations were conducted using an objective test method rather than an in vivo test method to eliminate the effects of variability of an individual skin on the attained friction measurements.

\subsection{The Friction Coefficient Across Four Control Surfaces}

The recorded COF values suggest that the surface materials' physical features could influence skin friction because patterned polycarbonate was the roughest whilst silicon surrogate skin was the most elastic and softest contact surface material. Previous studies have shown that the amplitude of the contact surface roughness has a dominant influence on the friction behaviour [12, 17, 28, 29], where the rougher the contact surface, the lower the friction. This study was conducted with surrogate skins. However, in experiments based on the human skin-textile interaction, the physical and physiological features of skin could influence friction behaviour [17, 19, 30-35], as well as the body testing location could influence friction behaviour [17, 24, 31, 32, 34, 36, 37]. Moreover, Yin et al. investigated that the physical properties of the textiles, i.e., roughness, and environmental conditions, influenced skin friction and pleasantness sensation [19]. To understand the skin's physical and physiological behaviour under friction, conducting skin-textile based future investigations is essential.

\subsection{The Repeatability of the Novel Friction Device}

Friction coefficient between the textile and fixed flat contact surfaces (transparent and patterned polycarbonate plastic, silicon, and Lorica surrogate skin) were measured three times per day across five consecutive days.
Fig. 6 The relationship between the static and dynamic friction coefficient for Transparent polycarbonate (a), Patterned polycarbonate (b), Surrogate skin-silicon (c) and Surrogate skin-Lorica (d) contact materials a

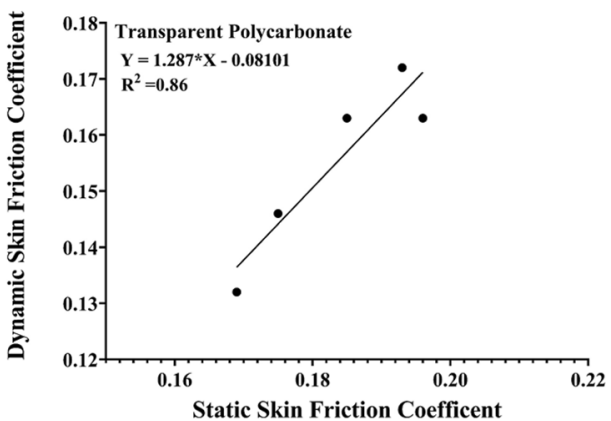

C

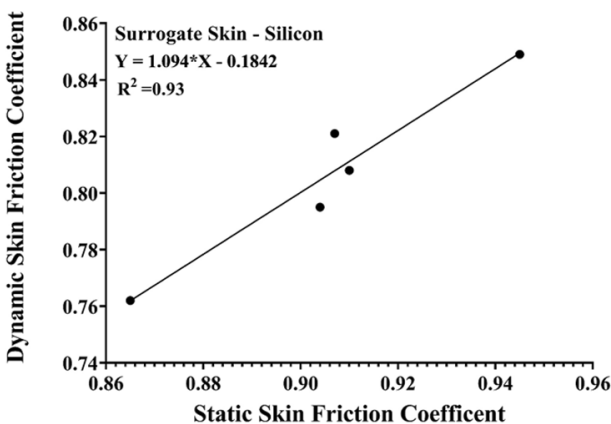

b

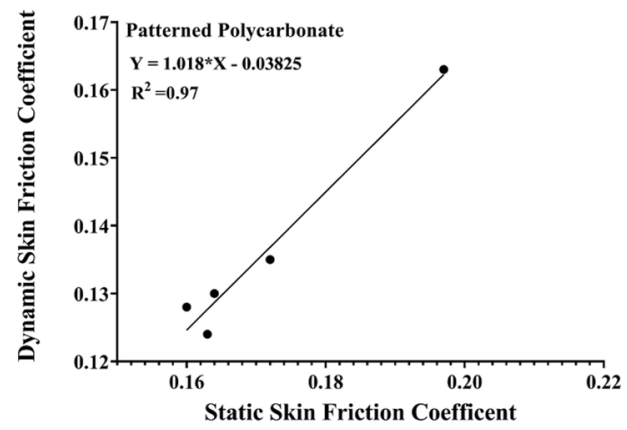

d

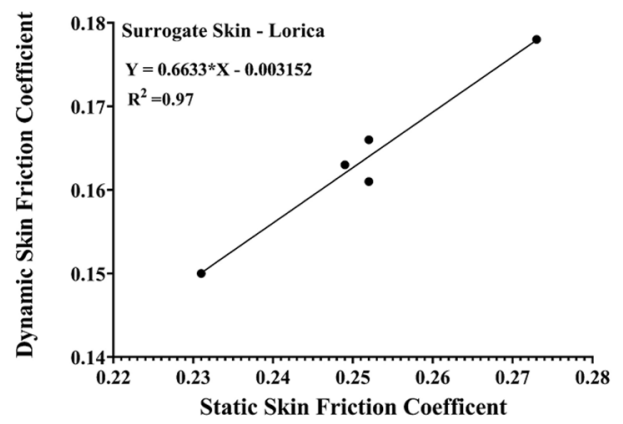


This study showed that the novel friction measurement device was highly reliable in its operation and data collection. Results from this study demonstrate that static and dynamic COF measurements had 2.22 and $3.15 \%$ of RPSD along with 0.94 and 0.93 ICC, respectively, which represented excellent repeatability and reliability. For context, guidelines defining ICC values greater than 0.75 as good reliability while values greater than 0.90 is expressed as excellent reliability [27].

Although the device measured the friction coefficient between the textile and surrogate skins with excellent repeatability, the skin's physical and physiological conditions (underneath structure, skin hydration, temperature and presence of hair, etc.) which contribute to their friction coefficient [38] may influence the repeatability of the device. To further demonstrate the capabilities of the established device an additional investigation that seeks to understand the human skin-textile interaction across a range of human body test sites with varying anatomical features and their impact on the repeatability of the device is needed.

\subsection{The Relationship Between Static and Dynamic Friction Coefficient}

It is known that the static $\mathrm{COF}$ is always greater than the dynamic COF and Veijgen et al. [38] found a strong correlation between the static and dynamic coefficient of friction. This relationship is linear, with an $\mathrm{r}^{2}$ of 0.97 , and can be described: $\mu_{\text {dynamic }}=0.85 \times \mu_{\text {static }}$. However, there has been no known study that has investigated how the features of interaction materials influence the relationship between static and dynamic COF. This study showed that the relationship between the static and dynamic COF is dependent on the surface properties of the materials being tested. As seen in Fig. 6, the relationship and prediction equation between static and dynamic friction coefficient changed based on control surface materials. In addition, the most significant magnitude between the static and dynamic COF was exhibited when using silicon surrogate skin as the contact material, while the transparent and patterned polycarbonate contact material had the lowest. The static skin friction force is the maximum force that can be applied perpendicular to a given normal force without moving. Therefore, the magnitude between the static and dynamic COF can be related to the degree of elasticity or stickiness of surface material, which is resistant to the first movement. The mechanical properties of the contact surfaces, i.e., roughness, stiffness, thickness, compression and resistance to shear, were not measured and therefore is a limitation of the current study. A further study focusing on the relationship between the static and dynamic COF is suggested to develop a greater insight into this behaviour.

\section{Conclusion}

The present study provides a detailed description relating to the development and evaluation of a novel customengineered device that could have the potential to reliably and conveniently measuring skin friction. Key findings from this study include:

(1) The novel device is portable, features interchangeable linearly moving test probes, works with user-friendly software, and has normal load, velocity, and motor speed values, that can be adjusted according to the experimental requirements.

(2) The newly established device can successfully measure the friction coefficient in textile-surface material interaction with an excellent level of repeatability.

(3) The silicon surrogate skin had the highest friction coefficient while the patterned polycarbonate plate had the lowest, suggesting that the physical features of the contact surface can influence recorded coefficient of friction values.

(4) The relationship between static and dynamic skin friction coefficient is dependent on the features of the interacting materials. It is important to understand the interpretation of static and dynamic friction coefficient in the context of skin-textile connection.

The findings from this work are key in providing a reliable device for measuring COF in skin-textile interaction and consequently supporting the wider bio tribology research field.

Acknowledgements I would like to thank Mr Dave Harris of Loughborough University's School of Design \& Creative Arts for supporting the manufacture of the novel friction testing device.

Author Contributions All authors contributed to the study conception and design. Material preparation, data collection and analysis were performed by Mevra Temel. Manuscript creation was led by Mevra Temel with input from the co-authors.

Funding This research was financially supported by a Ministry of National Education (the Republic of Turkey) PhD scholarship.

\section{Declarations}

Conflict of interest The authors declare that there are no conflicts of interests within the outlined work.

Open Access This article is licensed under a Creative Commons Attribution 4.0 International License, which permits use, sharing, adaptation, distribution and reproduction in any medium or format, as long as you give appropriate credit to the original author(s) and the source, provide a link to the Creative Commons licence, and indicate if changes were made. The images or other third party material in this article are included in the article's Creative Commons licence, unless indicated 
otherwise in a credit line to the material. If material is not included in the article's Creative Commons licence and your intended use is not permitted by statutory regulation or exceeds the permitted use, you will need to obtain permission directly from the copyright holder. To view a copy of this licence, visit http://creativecommons.org/licenses/by/4.0/.

\section{References}

1. Hatch, K.L., Markee, N.L., Maibach, H.I.: Skin response to fabric. A review of studies and assessment methods. Cloth. Text. Res. J. 10, 54-63 (1992). https://doi.org/10.1177/0887302X92 01000409

2. Gerrett, N., Ouzzahra, Y., Havenith, G.: Distribution of skin thermal sensitivity. In: Humbert, P. (ed.) Agache's measuring the skin, pp. 1285-1301. Springer, Dordrecht (2015)

3. Fukazawa, T., Havenith, G.: Differences in comfort perception in relation to local and whole body skin wettedness. Eur. J. Appl. Physiol. 106, 15-24 (2009). https://doi.org/10.1007/ s00421-009-0983-z

4. Ouzzahra, Y., Havenith, G., Redortier, B.: Regional distribution of thermal sensitivity to cold at rest and during mild exercise in males. J. Therm. Biol. 37, 517-523 (2012). https://doi.org/10. 1016/j.jtherbio.2012.06.003

5. Filingeri, D., Redortier, B., Hodder, S., Havenith, G.: Thermal and tactile interactions in the perception of local skin wetness at rest and during exercise in thermo-neutral and warm environments. Neuroscience 258, 121-130 (2014). https://doi.org/10.1016/j. neuroscience.2013.11.019

6. Havenith, G., van de Linde, E.J.G., Heus, R.: Pain, thermal sensation and cooling rates of hands while touching cold materials. Eur. J. Appl. Physiol. Occup. Physiol. 65, 43-51 (1992). https://doi. org/10.1007/BF01466273

7. Gerhardt, L.C., Mattle, N., Schrade, G.U., Spencer, N.D., Derler, S.: Study of skin-fabric interactions of relevance to decubitus: Friction and contact-pressure measurements. Ski. Res. Technol. 14, 77-88 (2008). https://doi.org/10.1111/j.1600-0846.2007. 00264.x

8. Ramalho, A., Szekeres, P., Fernandes, E.: Friction and tactile perception of textile fabrics. Tribol. Int. 63, 29-33 (2013)

9. Vilhena, L.M., Ramalho, A.: Friction behavior of human sSkin rubbing against different textured polymeric materials obtained by a 3D printing microfabrication technique. Tribol. Trans. 62, 324-336 (2019). https://doi.org/10.1080/10402004.2018.15437 82

10. Temel, M., Johnson, A.A., Havenith, G., Arnold, J.T., West, A.M., Lloyd, A.B.: An examination of five theoretical foundations associated with localized thermosensory testing. Eur. J. (2021). https:// doi.org/10.1007/s00421-021-04670-z

11. Derler, S., Scheel-Sailer, A., Stämpfli, R., Pille, D., Rossi, R.M., Rotaru, G.-M., Lehmeier, F.K.: Friction between human skin and medical textiles for decubitus prevention. Tribol. Int. 65, 91-96 (2013). https://doi.org/10.1016/j.triboint.2013.02.005

12. Derler, S., Gerhardt, L.C.: Tribology of skin: review and analysis of experimental results for the friction coefficient of human skin. Trobiol. Lett. (2012). https://doi.org/10.1007/s11249-011-9854-y

13. Sulzberger, M.B., Cortese, T.A., Fishman, L., Wiley, H.S.: Studies on blisters produced by friction. I. Results of linear rubbing and twisting technics. J. Invest. Dermatol. 47, 456-465 (1966). https:// doi.org/10.1038/jid.1966.169

14. Li, W., Kong, M., Liu, X.D., Zhou, Z.R.: Tribological behavior of scar skin and prosthetic skin in vivo. Tribol. Int. 41, 640-647 (2008). https://doi.org/10.1016/j.triboint.2007.11.009
15. Raccuglia, M., Pistak, K., Heyde, C., Qu, J., Mao, N., Hodder, S., Havenith, G.: Human wetness perception of fabrics under dynamic skin contact. Text. Res. J. 88, 2155-2168 (2017). https://doi.org/ 10.1177/0040517517716905

16. Raccuglia, M., Hodder, S., Havenith, G.: Human wetness perception in relation to textile water absorption parameters under static skin contact. Text. Res. J. 87, 2449-2463 (2016). https://doi.org/ 10.1177/0040517516671127

17. Hendriks, C.P., Franklin, S.E.: Influence of surface roughness, material and climate conditions on the friction of human skin. Tribol. Lett. 37, 361-373 (2010). https://doi.org/10.1007/ s11249-009-9530-7

18. Zhong, W., Xing, M.M.Q., Pan, N., Maibach, H.I.: Textiles and human skin, microclimate, cutaneous reactions: an overview. Cutan. Ocul. Toxicol. 25, 23-39 (2006). https://doi.org/10.1080/ 15569520500536600

19. Yin, L., Shim, E., DenHartog, E.: A study of skin physiology, sensation and friction of nonwoven fabrics used in absorbent hygiene products in neutral and warm environments. Biotribology. 24, 100149 (2020). https://doi.org/10.1016/j.biotri.2020.100149

20. Adams, M.J., Briscoe, B.J., Johnson, S.A.: Friction and lubrication of human skin. Tribol. Lett. 26, 239-253 (2007). https://doi.org/ 10.1007/s11249-007-9206-0

21. Gee, M.G., Tomlins, P., Calver, A., Darling, R.H., Rides, M.: A new friction measurement system for the frictional component of touch. Wear 259, 1437-1442 (2005). https://doi.org/10.1016/j. wear.2005.02.053

22. Masen, M.A., Veijgen, N., Klaassen, M.: Experimental tribology of human skin. Stud. Mechanbiol. (2019). https://doi.org/10.1007/ 978-3-030-13279-8_10

23. Veijgen, N.K., Masen, M.A., Van Der Heide, E.: A novel approach to measuring the frictional behaviour of human skin in vivo. Tribol. Int. 54, 38-41 (2012). https://doi.org/10.1016/j.triboint.2012. 05.022

24. Zhang, M., Mak, A.F.T.: In vivo friction properties of human skin. Prosthet. Orthot. Int. 23, 135-141 (1999). https://doi.org/10.3109/ 03093649909071625

25. Comaish, J.S., Harborow, P.R.H., Hofman, D.A.: A hand-held friction meter. Br. J. Dermatol. 89, 33-35 (1973). https://doi.org/ 10.1111/j.1365-2133.1973.tb01914.x

26. Ackerley, R., Saar, K., McGlone, F., Backlund Wasling, H.: Quantifying the sensory and emotional perception of touch: differences between glabrous and hairy skin. Front. Behav. Neurosci. 8, 1-12 (2014). https://doi.org/10.3389/fnbeh.2014.00034

27. Koo, T.K., Li, M.Y.: A guideline of selecting and reporting intraclass correlation coefficients for reliability research. J. Chiropr. Med. 15, 155-163 (2016). https://doi.org/10.1016/j.jcm.2016.02. 012

28. Derler, S., Gerhardt, L.C., Lenz, A., Bertaux, E., Hadad, M.: Friction of human skin against smooth and rough glass as a function of the contact pressure. Tribol. Int. 42, 1565-1574 (2009). https:// doi.org/10.1016/j.triboint.2008.11.009

29. Masen, M.A.: A systems based experimental approach to tactile friction. J. Mech. Behav. Biomed. Mater. 4, 1620-1626 (2011). https://doi.org/10.1016/j.jmbbm.2011.04.007

30. Gerhardt, L.C., Strässle, V., Lenz, A., Spencer, N.D., Derler, S.: Influence of epidermal hydration on the friction of human skin against textiles. J. R. Soc. Interface. 5, 1317-1328 (2008). https:// doi.org/10.1098/rsif.2008.0034

31. Gitis, N., Sivamani, R.: Tribometrology of skin. Tribol. Trans. 47, 461-469 (2004). https://doi.org/10.1080/05698190490493355

32. Koudine, B., Anthoine, A.: Frictional properties of skin: proposal of a new approach. Int. J. Cosmet. Sci. 22, 11-20 (2000). https:// doi.org/10.1046/j.1467-2494.2000.00006.x

33. Tomlinson, S.E., Lewis, R., Liu, X., Texier, C., Carré, M.J.: Understanding the friction mechanisms between the human finger 
and flat contacting surfaces in moist conditions. Tribol. Lett. 41, 283-294 (2011). https://doi.org/10.1007/s11249-010-9709-y

34. Zhu, Y.H., Song, S.P., Luo, W., Elias, P.M., Man, M.Q.: Characterization of skin friction coefficient, and relationship to stratum corneum hydration in a normal chinese population. Skin Pharmacol. Physiol. 24, 81-86 (2011). https://doi.org/10.1159/000321993

35. Sivamani, R.K., Goodman, J., Gitis, N.V., Maibach, H.I.: Friction coefficient of skin in real-time. Ski. Res. Technol. 9, 235-239 (2003). https://doi.org/10.1034/j.1600-0846.2003.20361.x

36. Cua, A.B., Wilhelm, K.P., Maibach, H.I.: Frictional properties of human skin: Relation to age, sex and anatomical region, stratum corneum hydration and transepidermal water loss. Br. J. Dermatol. 123, 473-479 (1990). https://doi.org/10.1111/j.1365-2133.1990. tb01452.x
37. Fagiani, R., Massi, F., Chatelet, E., Berthier, Y., Akay, A.: Tactile perception by friction induced vibrations. Tribol. Int. 44, 11001110 (2011). https://doi.org/10.1016/j.triboint.2011.03.019

38. Veijgen, N.K., Masen, M.A., van der Heide, E.: Variables influencing the frictional behaviour of in vivo human skin. J. Mech. Behav. Biomed. Mater. 28, 448-461 (2013). https://doi.org/10. 1016/j.jmbbm.2013.02.009

Publisher's Note Springer Nature remains neutral with regard to jurisdictional claims in published maps and institutional affiliations. 